\title{
What's in the Basket of Services? Support Preferences of Mental Health Consumers and Family Members
}

\author{
Nick Kerman, Susan Eckerle Curwood, Reena Sirohi, and John Trainor \\ Centre for Addiction and Mental Health
}

\begin{abstract}
This study explored mental health consumers' preferences regarding the support services needed to find, access, and maintain housing, and compared their views with the preferences of family members of consumers. A total of 354 consumers and 187 family members from across Canada completed questionnaires assessing their past and present experiences with housing and supports. Income supports and nutritional supports were described by both consumers and family members as the most important support services. Opinions diverged in other areas; consumers desired supports that fostered independent living, while family members emphasized services offering higher levels of support.
\end{abstract}

Keywords: consumer preferences, family members, mental illness, housing, support services

\section{RÉSUMÉ}

Cette étude a exploré les préférences des utilisateurs et utilisatrices de services de santé mentale concernant les services de soutien nécessaires pour trouver, obtenir et maintenir un logement, et a comparé ces préférences avec celles des membres des familles des utilisateurs et utilisatrices. Un total de 354 utilisateurs et utilisatrices et de 187 membres de famille, provenant des 4 coins du Canada, ont complété des questionnaires évaluant leur vécu antérieur et actuel en ce qui concerne le logement et les appuis. Les bénéfices de revenu et de nutrition ont été tous les deux décrits par les utilisateurs et utilisatrices et les membres de famille comme les services de soutien les plus importants. Les opinions ont divergé dans d'autres domaines; les utilisateurs et utilisatrices ont désiré des appuis favorisant le logement indépendant, tandis que les membres de famille ont accordé une importance particulière aux services offrant des niveaux de soutien plus élevés.

Mots clés : préférences des utilisateurs et utilisatrices, membres de famille, maladie mentale, logement, services de soutien

Nick Kerman, Community Support and Research Unit, Centre for Addiction and Mental Health; Susan Eckerle Curwood, Community Support and Research Unit, Centre for Addiction and Mental Health; Reena Sirohi, Community Support and Research Unit, Centre for Addiction and Mental Health; John Trainor, Community Support and Research Unit, Centre for Addiction and Mental Health.

The research was supported in part by a grant from the Mental Health Commission of Canada. We would like to thank Lianne Sprigg for her assistance with translation of the abstract.

Correspondence concerning this article should be addressed to Nick Kerman, Community Support and Research Unit, Centre for Addiction and Mental Health, Toronto, ON M6J 1H4. Email: Nick.Kerman@camh.ca 
Following deinstitutionalization in the 1960s and 1970s, housing and treatment for people with mental illness shifted, in part, from hospital to community (Friedrich, Hollingsworth, Hradek, Friedrich, \& Culp, 1999). Early evaluations on the impacts of deinstitutionalization concluded that, due in part to insufficient planning, the community supports available for people with mental illness did not meet the level of need (Bachrach, 1976, 1983). Decades later, shortages in support services still exist (Nelson, Aubry, \& Hutchison, 2009; Sealy \& Whitehead, 2006). Among the services for which supply currently does not match the level of need are assertive community treatment, case management, and community-based psychiatric care (Butterill et al., 2009). Lack of support for people with mental illness has resulted in increased rates of homelessness, incarceration, hospital readmission, and unemployment (Goering, Wasylenki, Farkas, Lancee, \& Freeman, 1984; Hughes, 1999; Nelson et al., 2009). In contrast, when people have the needed supports, recovery and quality of life are improved (Hughes, 1999).

The term "basket of services" refers to the services and supports required by people living with serious mental illness in order for them to live safe and productive lives in their communities (Kirby \& Keon, 2006). This definition is congruent with the intended outcomes of recovery-oriented services (e.g., assured personal safety, empowerment, self-development, equal opportunity, improved health; Anthony, 2000). Research into the components of a recovery-oriented basket of services can be divided into two streams. The first stream looks at the intangible features of support. For example, aspects such as choice, empowerment, and independence have been widely studied (e.g., Nelson, Sylvestre, Aubry, George, \& Trainor, 2007). The second stream of research, which consists of studies primarily conducted before the turn of the millennium, examines the material support services that need to be available to people with mental illness. Material clinical supports such as assertive community treatment, case management, and crisis services have been the predominant foci in this stream (for a review, see Goering et al., 1997), with few studies branching out beyond these core services. Yet, material supports refer not only to clinical services, but also to non-clinical services and supports such as income supports, education and employment supports, and life-skills training.

Due to the narrow focus of the research, traditional conceptions of the material basket of services have been fairly limited to the inclusion of only the aforementioned handful of clinical services. While these supports have been shown to be effective in increasing housing stability, and in improving symptomatology and subjective quality of life, evidence suggests that the material supports that are desired by and helpful to consumers go well beyond this small group of services. In a comprehensive review of consumers' housing and support service preferences, Tanzman (1993) found that income supports were the most frequently cited material support. Supports that enhanced accessibility were also in demand, with transportation and telephones being widely cited. Further research into consumer preferences has affirmed the value of income supports and transportation to consumers, as well as the desire for more peer support and employment support (Forchuk, Nelson, \& Hall, 2006; Grenville, 2000). However, the research in this area is mostly older and largely piecemeal, with few studies examining more than a couple of support services. As mental health systems continue to work toward developing more community-based resources, additional research is needed to better understand the supports most desired by people with mental illness and to determine whether the findings from early research on consumer preferences are still applicable. This paper will expand upon earlier research by examining consumers' preferences for a wide range of support services. Accordingly, the first goal of this paper is to determine which material supports consumers consider to be most important in assisting people living with mental illness to maintain their housing. 
Family members of people living with mental illness often carry a great burden throughout the recovery process (for a review, see Saunders, 2003). They believe that they have a vital role to play in service planning, development, delivery, and evaluation for their consumer relatives, but often feel that their opinions are lower on the hierarchy of service input than are those of other stakeholders, such as service users and providers (Lakeman, 2008; Rogers, Danley, Anthony, Martin, \& Walsh, 1994). The result is that family members often feel excluded from their loved one's treatment (Brown \& Birtwistle, 1998). Yet, caregiver burden is aggravated further if safe, permanent housing and support options are not available for their consumer relatives (Francell, Conn, \& Gray, 1988). Burnout is a common outcome for family members. However, the stress on family members may be alleviated if they are comfortable with their relatives' living situations. Because of this, it is important to ascertain what material supports are considered important by consumers' families.

The research that has examined family members' housing and support preferences is notably smaller than the body of work on consumer preferences, and has utilized the same limited focus. Several studies have compared and contrasted the preferences of consumers against those of family members. Findings suggest that the preferences of family members and consumers are similar; however, the groups do differ when it comes to the level of support they feel is optimal (Noble \& Douglas, 2004; Rogers et al., 1994). For example, family members more frequently endorse medication management (Fischer, Shumway, \& Owen, 2002; Rogers et al., 1994), 24-hour on-site supports (Friedrich et al., 1999), and daily living skills (Rogers et al., 1994). In contrast, consumers have been found to desire supports that enable greater independence (e.g., supports for finding and maintaining a house or an apartment; Fischer et al., 2002; Noble \& Douglas, 2004; Rogers et al., 1994). However, due to the small amount of research, comparisons of consumers' and family members' support preferences are scarce in other areas. For example, no study has compared these groups' views on employment and education supports, meal preparation and nutritional supports, or liaison services for communication with landlords and bylaw officers. Hence, the second goal of this paper is to further investigate the similarities and differences between consumers' and family members' support service preferences.

In this paper, we expand on the existing body of work and update the knowledge base on support service preferences for people living with mental illness by addressing the following two questions: (1) Which material supports are considered most important by family members and consumers in assisting people with mental illness to maintain their housing? (2) To what extent do the viewpoints of consumers differ from those of family members?

\section{METHODS}

The analyses for this study are based on data obtained from the Mental Health Commission of Canada's Turning the Key: Assessing Housing and Related Supports for Persons Living With Mental Health Problems and Illnesses project and report. The Turning the Key project was conducted by the Community Support and Research Unit of the Centre for Addiction and Mental Health and the Canadian Council on Social Development to identify the current housing and community support needs of people living with mental illness in Canada. Funded by the Mental Health Commission of Canada, the project was designed to assist with support planning and policy work in housing and related supports. As part of the project, question- 
naires for mental health consumers and family members were developed to learn about their housing and community support experiences.

\section{Sampling}

This study employed a chain-referral sampling methodology because of its effectiveness in reaching a large sample in a short period of time and in locating members of special populations to explore sensitive issues (Faugier \& Sargeant, 1997). The approach also enabled us to use the Turning the Key project's provincial and territorial advisory groups ${ }^{1}$ as regional jumping-off points for distributing the questionnaires.

Email invitations containing hyperlinks to the questionnaires and printable versions of the questionnaires were sent to compiled databases of individuals working with mental health agencies, and social and dedicated housing agencies, as well as to the provincial and territorial advisory groups. Recipients of the email invitations were asked to distribute and make available the questionnaire to consumers and family members, and circulate the email throughout their networks.

A total of 541 respondents completed the questionnaires. Participants were required to meet the following inclusion criteria: currently living in Canada, 18 years or older, and either a person living with a mental illness or a family member of someone living with a mental illness. Of the 354 participants who completed the questionnaire for consumers, 16 were excluded from analysis for reporting that they did not have a mental illness. Similarly, of the 187 respondents who completed the questionnaire for family members, 10 were excluded for indicating that they did not have a relative with a mental illness. No other participants were excluded from analysis.

Participation in the study was voluntary. All participants provided informed consent. The research project received approval from the Centre for Addiction and Mental Health's Research Ethics Board.

\section{Measures}

Separate questionnaires were created for consumers and family members to assess past and present experiences with housing and related supports. Aside from several yes/no and Likert-scale questions, the questionnaires used a list format whereby participants were presented with lists of responses from which to select. Respondents were also given the opportunity to provide "other" responses for all list questions. The only difference in data collected from the two questionnaires was in an added question for family members that inquired about the province/territory where their relative was living.

Sociodemographic information collected included provincial/territorial location, Aboriginal status (First Nations, Métis, or Inuit), and diagnostic information (a mental illness and/or an addiction). Housing and support service data collected by the questionnaires are detailed in Table 1. In the questions addressing support services considered to be most important for keeping housing, mental health, addictions, crisis, and, in part, housing support services were assessed as overall categories. Because of this, respondents were also asked to specify the services within each domain that they believed to be most important. 


\section{Table 1}

\section{Housing and Support Service Areas Assessed}

Areas assessed
(number and format of items)

Housing

1. Current living arrangement $(11$, list $)$

You rent an apartment that is meant only for people living with mental health problems/illness and/or an addiction; you own your own home; you are living with your family; you are living on the streets

2. Current housing satisfaction (3, yes/somewhat/no)

3. Desire to move (2, yes/no)

4. Challenges experienced in finding, accessing, or keeping housing $\left(10\right.$, list $\left.^{\mathrm{a}}\right)$

Finding housing that is affordable; being discriminated against when trying to find/keep housing; having the supports I need to stay in my home

5. Recommendations to improve housing for people with mental illness $\left(15\right.$, list $\left.^{\mathrm{a}}\right)$

Put more effort into building new housing instead of research and planning; people need access to peer support; supports are needed to help people build life skills like financial management

Support services

1. Services utilized and difficulties experienced accessing them $\left(9\right.$, list $\left.^{\mathrm{a}}\right)$

Community nurse; family doctor; housekeeping services; housing support services; language services; literacy program; meal preparation services

2. Perceptions of service effectiveness (2, 7-point Likert)

There were services in the community that helped me to find my housing; the services I use help me to keep my housing

3. Services considered to be most

Crisis services; employment support; income supports; life-skills important for keeping housing $\left(24\right.$, list $\left.^{\mathrm{a}}\right)$ training; mental health services; peer support (see Table 3 for a complete list of services)

Notes. Response examples are listed as they appear in the consumers' questionnaire.

a Question allowed participants to "select all that apply." 
Both questionnaires were available online and in hard copy format, in English and in French. We piloted the questionnaires over a 3-week period and made revisions based on feedback received. Individuals who responded to the questionnaires during the pilot phase were representatives of the questionnaires' target populations, and the provincial and territorial advisory groups. Ten consumers and four family members piloted their respective questionnaires.

Questionnaires were made available online from April 2010 to June 2010. We accepted hard copy questionnaires for 2 weeks after the online closing date to accommodate any delays in mail delivery.

\section{Data Analysis}

Support service preferences of consumers and family members were determined by tallying the number of supports chosen by respondents as important for keeping housing. Between groups comparisons were conducted using chi-square tests. The same process was used for examining the challenges faced in finding, accessing, and keeping housing. Bonferroni corrections were applied to both sets of chi-square tests ( $p=.002$ was used for comparisons of support service preferences and $p=.005$ for comparisons of housing challenges). Additionally, independent samples t-tests were used to test respondents' judgments on the effectiveness of support services in assisting people to find and maintain housing. For analyses in which Levene's test for equality of variances was significant $(p \leq .05)$, the unequal estimate of $t$ is presented. SPSS 15.0 was used for all analyses.

\section{RESULTS}

\section{Sample Characteristics}

Mental health consumers $(\boldsymbol{n}=\mathbf{3 3 8})$. Most respondents $(74.6 \%)$ reported having only a mental illness, while one quarter (25.4\%) had a concurrent disorder. The living arrangements of consumers varied, but the most common were renting an apartment/house not dedicated for mental health consumers $(37.3 \%)$, renting an apartment/house dedicated for mental health consumers (26.6\%), owning a home (12.1\%), or living with family (6.2\%). Twenty consumers (5.9\%) reported Aboriginal status. All provinces and territories except the Northwest Territories and Nunavut were represented by consumers; a full breakdown of participation by province and territory is listed in Table 2 .

Family members $(\boldsymbol{n}=\mathbf{1 7 7})$. Slightly under two thirds of family members $(64.4 \%)$ reported that their relatives had only a mental illness, while a little over one third (35.6\%) noted having a family member with a concurrent disorder. Family members reported that their relatives lived in one of the following arrangements: rented an apartment/house not dedicated for mental health consumers (31.1\%), lived with the family member respondent (26.0\%), rented an apartment/house dedicated for mental health consumers $(12.4 \%)$, owned a home $(8.5 \%)$, or lived with other family members (6.2\%). Eight respondents $(4.5 \%)$ were of Aboriginal status. Table 2 lists the provincial and territorial representation of family members. 
Table 2

Sample Representation by Province and Territory

\begin{tabular}{lrrrrr}
\hline & \multicolumn{2}{c}{ Consumers } & & \multicolumn{2}{c}{ Family members } \\
\cline { 2 - 3 } \cline { 5 - 6 } Province/Territory & $n^{\mathrm{a}}$ & $\%$ & & $n^{\mathrm{b}}$ & $\%$ \\
\hline Alberta & 22 & 6.5 & & 13 & 7.3 \\
British Columbia & 82 & 24.3 & & 36 & 20.3 \\
Manitoba & 4 & 1.2 & & 1 & 0.6 \\
New Brunswick & 3 & 0.9 & & 6 & 3.4 \\
Newfoundland and Labrador & 12 & 3.6 & & 5 & 2.8 \\
Nova Scotia & 18 & 5.3 & & 5 & 2.8 \\
Nunavut & 0 & 0 & & 1 & 0.6 \\
Ontario & 154 & 45.6 & & 0 & 49.2 \\
Prince Edward Island & 6 & 1.8 & & 6 & 0 \\
Quebec & 16 & 4.7 & & 16 & 3.4 \\
Saskatchewan & 15 & 4.4 & & 1 & 0.6 \\
Yukon & 3 & 0.9 & & & 0.6 \\
\hline
\end{tabular}

Notes. ${ }^{\mathrm{a}} n=335$. (Three consumers did not specify the province or territory that they resided in.) ${ }^{\mathrm{b}} n=177$.

\section{Support Services as a Defence Against Housing Challenges}

Critical challenges in finding, accessing, and keeping housing were described by participants. Among respondents who reported challenges (285 consumers and 160 family members), finding affordable housing was the concern most commonly reported by both groups. However, significantly more consumers reported facing this problem $(80.0 \%)$ than did family members reporting on the experiences of their relatives $(64.4 \%)$, $\chi^{2}(1)=13.13, p<.001$. Perception of the needed supports to maintain housing was the greatest difference between the two groups. For family members, this was the most frequently cited challenge beyond the issue of affordability $(55.0 \%)$, while a little over one quarter of consumers $(28.4 \%)$ reported experiencing this problem, $\chi^{2}(1)=30.73, p<.001$. Together, nearly two in every five respondents $(38.0 \%)$ indicated that they or their consumer relatives had faced challenges due to a lack of supports needed to stay in their homes.

Consumers generally considered support services to be effective in helping people find and maintain housing. In contrast, family members were less certain about the effectiveness of these services. Using a 7-point scale ranging from 1 (strongly disagree) to 7 (strongly agree), consumers agreed that there were community services that helped them find $(M=4.83, S D=2.24)$ and maintain $(M=5.14, S D=2.02)$ housing. These opinions differed significantly from those of family members, who slightly disagreed that there were services in the community to help their consumer relatives find housing $(M=3.56, S D=2.18), t(400)=$ $5.29, p<.001$. Family members also neither agreed nor disagreed with the statement that the services their 
relatives used helped them keep their housing $(M=4.03, S D=2.18), t(367)=4.78, p<.001$. Family member respondents whose consumer relatives were living with them agreed even less that there were services to help their relatives find housing $(M=2.77, S D=1.77)$ than did family members whose consumer relatives were not living with them $(M=3.69, S D=2.23), t(37.52)=2.10, p=.043$. Participants perceived community services to be no more or less effective for consumers with a concurrent disorder or a mental illness only.

\section{Support Service Preferences}

Income and nutritional supports were described by both consumers and family members as the most important support services. Three quarters of consumer (74.8\%) and family member $(75.6 \%)$ respondents reported income supports as one of the most important support services to help people with mental illness maintain their housing, making it the most frequently cited support. The only other support service cited by more than $70 \%$ of sample respondents overall was nutritional supports. A greater percentage of consumers (74.5\%) identified nutritional supports as an important support service than did family members (67.3\%); however, the difference was not significant.

The opinions of consumers and family members differed significantly on four supports. Most notably, medication management was second only to income supports as one of the most important supports cited by family members $(68.5 \%)$, while just over half of consumers $(51.0 \%)$ were in agreement, $\chi^{2}(1)=13.67$, $p<.001$. Assistance with meal preparation was the only other support selected by significantly more family members than consumers, while having access to a family doctor and language services were selected more frequently by consumers. Education supports, culture-specific supports, and literacy programs were also identified by more consumers than family members but did not reach the level of significance. On average, family members identified slightly fewer support services than consumers, 11.7 and 12.1 support services per respondent, respectively; this difference was not significant. For a full listing of the support services desired by consumers and family members, and the differences between the two groups, see Table 3 .

Respondents were also asked to identify specific mental health, addictions, crisis, and housing support services that they believed to be most important. The tangible mental health services most frequently identified by both family member and consumer participants were psychiatrists, case managers, and assertive community treatment teams. In addictions, the services commonly cited included harm reduction programs, Alcoholics Anonymous, and counselling services. Participants reported a great variety of desired crisis services. Among the most common responses were crisis telephone lines, mobile crisis teams, respite beds, suicide prevention services, and peer support options for crisis situations. Finally, the housing support services specified by consumers and family members reflected varying levels of need and desires for support. Beyond the housing support services already listed in the questionnaires (e.g., hygiene support, meal preparation, and housekeeping services), popular supports identified by respondents included on-call housing support workers around the clock and assistance with budgeting, home maintenance, and housing communication (e.g., responding to rent increases or complaints). 
Table 3

Consumer and Family Member Support Service Preferences

\begin{tabular}{|c|c|c|c|c|c|c|}
\hline \multirow[b]{2}{*}{ Support service } & \multicolumn{2}{|c|}{ Consumers } & \multicolumn{2}{|c|}{ Family members } & \multirow[b]{2}{*}{$\chi^{2 \mathrm{c}}$} & \multirow[b]{2}{*}{$p^{\mathrm{d}}$} \\
\hline & $n^{\mathrm{a}}$ & $\%$ & $n^{\mathrm{b}}$ & $\%$ & & \\
\hline Income supports & 235 & 74.8 & 127 & 75.6 & 0.03 & .855 \\
\hline Nutritional supports ${ }^{\mathrm{e}}$ & 234 & 74.5 & 113 & 67.3 & 2.86 & .091 \\
\hline Mental health services & 214 & 68.2 & 115 & 68.5 & 0.01 & .946 \\
\hline Employment supports & 199 & 63.4 & 104 & 61.9 & 0.10 & .750 \\
\hline Life-skills training & 193 & 61.5 & 106 & 63.1 & 0.12 & .725 \\
\hline Supports to help find housing & 186 & 59.2 & 102 & 60.7 & 0.10 & .752 \\
\hline Family doctor & 206 & 65.6 & 80 & 47.6 & 14.67 & $<.001$ \\
\hline Recreation activities & 187 & 59.6 & 98 & 58.3 & 0.07 & .795 \\
\hline Medication management & 160 & 51.0 & 115 & 68.5 & 13.67 & $<.001$ \\
\hline Education supports & 188 & 59.9 & 84 & 50.0 & 4.34 & .037 \\
\hline Community activities & 177 & 56.4 & 94 & 56.0 & 0.01 & .930 \\
\hline Landlord liaisons & 182 & 58.0 & 86 & 51.2 & 2.03 & .154 \\
\hline Crisis services & 159 & 50.6 & 82 & 48.8 & 0.15 & .702 \\
\hline Peer support & 155 & 49.4 & 71 & 42.3 & 2.22 & .137 \\
\hline Community nurse & 151 & 48.1 & 75 & 44.6 & 0.52 & .470 \\
\hline Housing support services ${ }^{f}$ & 144 & 45.9 & 73 & 43.5 & 0.26 & .613 \\
\hline Hygiene support & 132 & 42.0 & 83 & 49.4 & 2.40 & .121 \\
\hline Meal preparation & 105 & 33.4 & 91 & 54.2 & 19.49 & $<.001$ \\
\hline Addictions services & 121 & 38.5 & 60 & 35.7 & 0.37 & .542 \\
\hline Housekeeping & 109 & 34.7 & 59 & 35.1 & 0.01 & .929 \\
\hline Bylaw officer liaisons & 108 & 34.4 & 55 & 32.7 & 0.13 & .714 \\
\hline Culture-specific supports & 96 & 30.6 & 34 & 20.2 & 5.94 & .015 \\
\hline Literacy program & 90 & 28.7 & 30 & 17.9 & 6.83 & .009 \\
\hline Language services & 78 & 24.8 & 21 & 12.5 & 10.21 & .001 \\
\hline
\end{tabular}

Notes. ${ }^{\mathrm{a}} n=314 .{ }^{\mathrm{b}} n=168 .{ }^{\mathrm{c}} d f=1$ for all chi-square tests. ${ }^{\mathrm{d}} \mathrm{A}$ Bonferroni correction was implemented such that tests

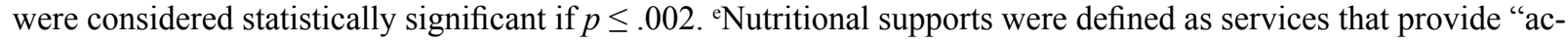
cess to healthy, affordable food." "Housing support was defined as "a variety of flexible, on-site supports that assist a person in maintaining their housing tenure (may include assistance with running a household, finances and budgeting, interpersonal relationships, and referrals to other clinical and non-clinical services).” 


\section{DISCUSSION}

\section{Most Critical Support Services}

Overall, consumers described support services as more helpful in finding and maintaining housing than did family members. However, both groups considered a number of support services very important in helping people with mental illness maintain their housing. Consistent with the findings from previous research (e.g., Forchuk et al., 2006; Tanzman, 1993), income supports were the most cited support service; three out of every four consumers identified income supports as essential for maintaining housing. Family members were also in agreement, as they too selected income supports more than any other support service. These findings further demonstrate the perceived necessity of income supports in maintaining housing and highlight the ongoing struggle for people with mental illness to access affordable housing.

Examination of current disability income rates in Canada reveals just how important financial assistance is for some people with mental illness. A recent report by the Organisation for Economic Co-operation and Development (2010) reveals that Canada's current disability income rates - at only about $20 \%$ of an average full-time wage - are among the lowest of OECD member countries. Income support recipients must therefore stretch a little money a long way. Especially in today's economic climate, characterized by rising housing costs, stagnant household incomes, and growing waiting lists for affordable housing (Wellesley Institute, 2010), the importance of income supports cannot be overstated.

With governments at all levels implementing austerity measures in recent years, it is highly unlikely that relief in the form of increased social assistance rates is on the horizon. Instead, progress will need to be made by tackling the deeper root of the problem - unemployment. The negative relation between mental illness and employment is well documented; it is estimated that as many as $90 \%$ of people with severe mental illness do not participate in the labour market (Kirby \& Keon, 2006). At the crux of the problem is an alarming trend in which more and more people entering social assistance programs are remaining on them for life (Organisation for Economic Co-operation and Development, 2003). Fundamental changes need to occur in social assistance systems and the policies that govern them in order for income support recipients to return to work. To make social assistance programs more responsive to recipients' needs and promote flow within the system, disincentives to working should be removed. For example, income support recipients should be allowed to participate in temporary paid work (which is often more harmonious with the episodic nature of mental illness), without having to reapply to the program when the job ends. Recipients in the current system have to continually demonstrate a disability to receive income support, which fosters a learned helplessness. A greater focus on recipients' capacities for work rather than their inabilities would better assist individuals to find jobs.

Nutritional supports for healthy and affordable eating were the second most frequently cited support service. Although occasionally obscured in research on support needs for people with mental illness by more prominent findings, the need for nutritional supports has been a concern for many years. For example, Friedrich et al. (1999) examined housing problems from consumers' and family members' perspectives and found poor nutrition to be the fifth most reported problem by consumers and the tenth by family members. A recent study of 1,200 people who were vulnerably housed or homeless in Canada indicates that food insecurity is a growing concern, as $27 \%$ were unable to acquire good quality food and $22 \%$ reported that their 
diets were not nutritious (Research Alliance for Canadian Homelessness, Housing, and Health, 2010). In addition to resulting in poor nutrition, food insecurity has been shown to increase the risk of heart disease, diabetes, high blood pressure, major depression and distress, and poor functional health (Vozoris \& Tarasuk, 2003). The negative correlation between food insecurity and income raises further cause for alarm given the perceived importance of income supports by people with mental illness, some of whom may rely on such financial assistance as their primary source of income.

To increase knowledge about the consequences of food insecurity and poor nutrition, and assist with healthy and affordable eating, policy makers and service providers need to put in place a variety of supports such as nutritionist and dietitian services, education on cooking and budgeting skills, and information on accessing local food banks. Collaboration among service providers is essential for the successful provision of nutritional supports, as problems of service underuse and inaccessibility are common among people with mental illness (Wilkinson \& Himstedt, 2008). With a coordinated network of service providers in place, people in need of services to assist with healthy and affordable eating can be informed of or connected with supports in an efficient manner. Promoting a greater focus on nutritional supports among service providers is a critical first step to addressing the need; however, before overhauling approaches to providing nutritional supports, decision makers should consult with experts and review the types of nutritional supports that are considered most effective and desired by consumers.

\section{Differences Between Mental Health Consumers and Family Members}

The opinions of consumers and family members in this study differed in a number of support service areas. Affirming earlier findings by Tanzman (1993), consumers identified the importance of supports that are available on an as-needed basis, such as having a family doctor, whereas family members placed greater emphasis on supports that are always present or available, such as medication management and meal preparation services. Overall, the top supports preferred by family members were more varied than those chosen by consumers. While family members identified the importance of more intensive supports, they also recognized the value of supports promoting independent living (e.g., employment supports, life-skills training). The preferences of consumers, on the other hand, primarily prioritized supports in this latter category. This pattern of findings partially coincides with past literature, which describes a divide in the perspectives of consumers and family members when it comes to the supports they value most. Family members have been shown to prefer more intensive supports for their relatives, whereas consumers desire supports that foster autonomy (Friedrich et al., 1999; Noble \& Douglas, 2004; Rogers et al., 1994). In this study, family members recognized the importance of both intensive supports and, to a lesser degree, supports that promote independent living and autonomy.

The findings have practical implications for the current era, in which housing models are breaking away from traditional, "custodial" approaches (e.g., board-and-care homes). Custodial housing models foster a dependency on staff and provide little in terms of rehabilitation or support that would enable residents to become more independent (Nelson, 2010). Our findings demonstrate that consumers place a high value on skill-building supports such as life-skills training, employment and education supports, and literacy programs, which are not harmonious with the custodial approach. The voices of consumers heard in this study prefer the newer, supported housing approach where tenants have more control over the services they receive and 
can more easily acquire supports to help them gain skills to further their recovery and become increasingly participatory members of society.

At first glance, family members' preference for supports that add a structural element to their relatives' lives - medication management and meal preparation services - would suggest that they support rigid housing models such as custodial housing. However, they also recognized the importance of supports related to skill development (e.g., employment supports and life-skills training), which would not be congruous with the custodial housing approach (Parkinson, Nelson, \& Horgan, 1999). An alternative explanation is that the findings may be indicative of family members' concern for the well-being and safety of their loved ones first and foremost. Preferences for medication management and meal preparation services may be the result of family members' worries about whether their relatives are taking their medicine and consuming a healthy diet. The push-and-pull that family members experience, between wanting their consumer relatives to live independently and being concerned for their health and safety, has been documented in past research. In a qualitative study by Browne and Hemsley (2010), family members stressed that their loved ones need choice and flexibility in supports to redevelop their living skills. However, they also agreed that safety is one of the cornerstones of housing, and that sometimes service providers may need to make decisions for their loved ones for safety reasons. Thus, the custodial housing approach satisfies family members' concern for their loved ones' safety but is not optimal in their view because it perpetuates staff dependency among residents. Other housing models are better able to accommodate the interests of family members by balancing support and participation in skill-building programs. For example, support staff can provide around-the-clock care, include tenants in treatment planning, and help them connect with employment services while also allowing tenants to choose the programs they wish to take part in and the life skills they would like to learn. Recoveryoriented housing models that offer flexible high support can balance the support needs and preferences of consumers and family members. However, many housing programs that offer high-intensity supports still do so in a way that does not reflect consumers' desire for growth and development. More action is needed in transitioning toward recovery-oriented housing models (e.g., supported housing) from outdated housing approaches that focus on maintenance and not recovery (e.g., board-and-care homes).

In this study, the percentage of family members who reported having relatives with concurrent disorders, and the percentage reporting relatives who were living at home with them, was higher than the percentages of consumer participants reporting concurrent disorders or living with family members, respectively. While the higher prevalence of concurrent disorders in the family members sample was not found to be related to any of the differing opinions between consumers and family members, the differences in reported housing arrangements may explain some of the differences of opinion between the two groups. Family members whose consumer relatives were living with them may have experienced those same relatives' past failures in finding or keeping housing. Family members reported feeling more uncertainty about the adequacy of services in the community than did consumers. Furthermore, family members whose consumer relatives were living with them exhibited even less confidence than the overall family members sample, suggesting that past efforts to find such services may have been unsuccessful, or that the services accessed had been ineffective. These family members may feel that they lack support from the mental health system, and that the onus is on them to take care of their consumer relatives. Some family members may view their consumer relatives' living with them to be a situation of last resort. In this arrangement, family members experience 
the burden of caring for their loved ones, but the living arrangement does ensure that the person with mental illness is safe and stably housed.

Despite a general consensus that income and nutritional supports are the most important support services for keeping housing, the wide variety of supports identified by respondents and the differing opinions between the two groups demonstrate the need for having a flexible basket of services that aligns with the needs and preferences of consumers and family members. The senate report Out of the Shadows at Last (Kirby \& Keon, 2006) first proposed the need for a basket of community services that would provide people with mental illness a range of services and supports to live safely in the community. The report highlighted three services to be at the core of a community-based mental health system - assertive community treatment, crisis intervention, and case management — but asserted that many other services could be involved, such as peer support, employment support, and culture-specific programs. While these services are important and necessary in any recovery-oriented basket of services, consumers and family members identify many other services that are critical for keeping housing and living healthy lives in the community. The Mental Health Commission of Canada's (2012) Changing Directions, Changing Lives: The Mental Health Strategy for Canada recognizes the critical need for a basket of services as it calls for increased availability of housing supports and peer support, and improvements to income, employment, and education support programs. While the strategy notes the importance of these supports, it is vague with regard to the specific supports that are in short supply and desperately needed by people with mental illness. Furthermore, in the strategy's list of potential indicators to be reported upon in a comprehensive mental health outcomes framework by 2017 , no measure of access and availability to support services is included, despite a strategic direction labelled "Access to Services." The Mental Health Commission of Canada should consider adding an indicator that monitors improvements in access to a wide range of support services and that reflects the preferences of consumers and family members. While mining existing data sources for this information may be difficult, it will go a long way toward identifying the priority areas and better understanding the support service needs of people with mental illness in Canada.

\section{Limitations and Future Research}

A number of limitations were present in this study. As this study had a non-random sample due to the chain-referral sampling methodology, the findings are not necessarily generalizable to the larger target population of people with mental illness. However, because several of the results from this study are strongly supported by previous research, the findings may not be limited to this sample. Chain-referral sampling methodologies have also been shown to produce differential recruitment patterns with individuals enlisting others to participate who have particular or similar characteristics, rather than recruiting at random (Erickson, 1979; Johnston \& Sabin, 2010). In this case, respondents with more social connections are likely overrepresented in the sample while more isolated individuals are likely underrepresented.

The design of the questionnaires also resulted in several limitations that suggest directions for future research. As the questionnaires assessed mental illness dichotomously as either the presence or absence of "a mental health problem or illness," there are concerns about the study's generalizability to subpopulations (e.g., people with "serious" mental illness). Further research is needed to investigate differences in the support

preferences of consumers whose levels of disability and support needs differ, and the preferences of their 
family members. Several support services were addressed as overall categories by the questionnaires: mental health, addictions, and crisis services. A greater examination of the specific supports within each domain would be beneficial to the body of work on consumers' and family members' support preferences. Although the questionnaires assessed support service use, we could not compare these responses with support service preferences due to differences in the structure of the questions. In future, researchers may want to consider examining preferences among consumers who have experience with the support services in question.

One final consideration for future research is to put in place measures to reduce circumstantial differences between consumer and family member participants. In this study, circumstantial differences in housing arrangements likely contributed to family members' perceptions that existing support services were generally not effective in helping their consumer relatives find and keep housing. Additionally, because the questionnaires were primarily distributed to individuals involved in the mental health system for further dissemination, it is likely that the consumers who received the questionnaires and participated in this study were connected with the mental health system, which may not have been the case for family members' consumer relatives. Researchers may want to consider recruiting related consumers and family members in order to minimize the differences between the two groups and achieve more lucid findings.

\section{CONCLUSION}

For many people with mental illness, supports are the critical factor in determining whether they are able to find and stay in their preferred housing (Carling, Randolph, Blanch, \& Ridgway, 1987, cited in Carling, 1993). Findings from this study demonstrate that mental health consumers believe a lack of support services can be detrimental to acquiring and maintaining housing, while having access to the needed supports can be beneficial. The study affirms the perceived importance of income supports by consumers and family members, while also revealing an array of other supports strongly regarded as important for maintaining housing. While consumers and family members were in agreement when it came to many supports, opinions did differ on a number of key supports including medication management, family doctors, and meal preparation services. The findings suggest that self-sufficiency is at the core of the groups' diverging opinions; consumers desired supports that fostered skill development and independent living, whereas family members prioritized more intensive supports that gave structure and security to their relatives' lives in addition to supports such as life-skills training and employment supports. The expansive range of supports identified by consumers and family members demonstrates that a recovery-oriented approach to the basket of services must be flexible. Just as housing models fit differently in consumers' lives (Leff et al., 2009), so too do the support services that go along with housing.

\section{NOTE}

1. The provincial and territorial advisory groups were composed of researchers and academics, mental health professionals, housing providers, policy makers, consumers, and family members who were knowledgeable in mental health and housing. 


\section{REFERENCES}

Anthony, W. A. (2000). A recovery-oriented service system: Setting some system level standards. Psychiatric Rehabilitation Journal, 24(2), 159-168.

Bachrach, L. L. (1976). Deinstitutionalization: An analytic review and sociological perspective (Department of Health, Education, and Welfare Publication No. ADM 76-351). Washington, DC: Government Printing Office.

Bachrach, L. L. (1983). New directions in deinstitutionalization planning. New Directions for Mental Health Services, 17, 93-106. doi:10.1002/yd.23319831710

Brown, S., \& Birtwistle, J. (1998). People with schizophrenia and their families: Fifteen-year outcome. British Journal of Psychiatry, 173, 139-144. doi:10.1192/bjp.173.2.139

Browne, G., \& Hemsley, M. (2010). Housing and living with a mental illness: Exploring carers' views. International Journal of Mental Health Nursing, 19, 22-29. doi:10.1111/j.1447-0349.2009.00635.x

Butterill, D., Lin, E., Durbin, J., Lunsky, Y., Urbanoski, K., \& Soberman, H. (2009). From hospital to home: The transitioning of alternate level of care and long-stay mental health clients. Retrieved from Centre for Addiction and Mental Health website, http://www.camh.net/Research/Areas_of_research/Social_Prevention_Health_Policy/ HSRCU/ALC\%20Report_FINAL4.pdf

Carling, P. J. (1993). Housing and supports for persons with mental illness: Emerging approaches to research and practice. Hospital and Community Psychiatry, 44(5), 439-449.

Erickson, B. H. (1979). Some problems of inference from chain data. Sociological Methodology, 10, 276-302. Retrieved from http://www.jstor.org/stable/270774

Faugier, J., \& Sargeant, M. (1997). Sampling hard to reach populations. Journal of Advanced Nursing, 26(4), 790-797. doi:10.1046/j.1365-2648.1997.00371.x

Fischer, E. P., Shumway, M., \& Owen, R. R. (2002). Priorities of consumers, providers, and family members in the treatment of schizophrenia. Psychiatric Services, 53(6), 724-729. doi:10.1176/appi.ps.53.6.724

Forchuk, C., Nelson, G., \& Hall, G. (2006). "It's important to be proud of the place you live in": Housing problems and preferences of psychiatric survivors. Perspectives in Psychiatric Care, 42, 42-52. doi:10.1111/j.1744-6163.2006.00054.x

Francell, C. G., Conn, V. S., \& Gray, D. P. (1988). Families' perceptions of burden of care for chronic mentally ill relatives. Hospital and Community Psychiatry, 39(12), 1296-1300.

Friedrich, R. M., Hollingsworth, B., Hradek, E., Friedrich, H. B., \& Culp, K. R. (1999). Family and client perspectives on alternative residential settings for persons with severe mental illness. Psychiatric Services, 50(4), 509-514. Retrieved from http://ps.psychiatryonline.org/journal.aspx?journalid=18

Goering, P., Boydell, K., Butterill, D., Cochrane, J., Durbin, J., Rogers, J., \& Trainor, J. (1997). Review of best practices in mental health reform. Retrieved from Public Health Agency of Canada website, http://www.phac-aspc.gc.ca/ $\mathrm{mh}$-sm/pubs/bp_review/pdf/e_bp-rev.pdf

Goering, P., Wasylenki, D., Farkas, M., Lancee, W., \& Freeman, S. J. (1984). From hospital to community: Sixmonth and two-year outcomes for 505 patients. Journal of Nervous and Mental Disease, 172, 667-673. doi:10.1097/00005053-198411000-00005

Grenville, R. (2000). Unspoken voices: The experiences and preferences of adult mental health consumers regarding housing and supports (Doctoral dissertation). Retrieved from https://dspace.ucalgary.ca/bitstream/1880/40519/ 1/54782Grenville.pdf

Hughes, W. C. (1999). Managed care, meet community support: Ten reasons to include direct support services in every behavioral health plan. Health and Social Work, 24(2), 103-111. doi:10.1093/hsw/24.2.103

Johnston, L. G., \& Sabin, K. (2010). Sampling hard-to-reach populations with respondent driven sampling. Methodological Innovations Online, 5(2), 38-48. doi:10.4256/mio.2010.0017

Kirby, M. J. L., \& Keon, W. J. (2006). Out of the shadows at last: Transforming mental health, mental illness and addiction services in Canada. Retrieved from Parliament of Canada website, http://www.parl.gc.ca/Content/SEN/ Committee/391/soci/rep/rep02may06part2-e.htm\#_Toc133223078

Lakeman, R. (2008). Family and carer participation in mental health care: Perspectives of consumers and carers in hospital and home care settings. Journal of Psychiatric and Mental Health Nursing, 15, 203-211. doi:10.1111/j.1365-2850.2007.01213.x 
Leff, H. S., Chow, C. M., Pepin, R., Conley, J., Allen, I. E., \& Seaman, C. A. (2009). Does one size fit all? What we can and can't learn from a meta-analysis of housing models for persons with mental illness. Psychiatric Services, 60, 473-482. doi:10.1176/appi.ps.60.4.473

Mental Health Commission of Canada. (2012). Changing directions, changing lives: The mental health strategy for Canada. Retrieved from http://strategy.mentalhealthcommission.ca/

Nelson, G. (2010). Housing for people with serious mental illness: Approaches, evidence, and transformative change. Journal of Sociology and Social Welfare, 37(4), 123-146. Retrieved from http://www.wmich.edu/hhs/ newsletters_journals/jssw/

Nelson, G., Aubry, T., \& Hutchison, J. (2009). Housing and mental health. In J. H. Stone \& M. Blouin (Eds.), International encyclopedia of rehabilitation. Retrieved from Center for International Rehabilitation Research Information and Exchange website, http://cirrie.buffalo.edu/encyclopedia/en/article/132/

Nelson, G., Sylvestre, J., Aubry, T., George, L., \& Trainor, J. (2007). Housing choice and control, housing quality, and control over professional support as contributors to the subjective quality of life and community adaptation of people with severe mental illness. Administration and Policy in Mental Health Services Research, 34(2), 89-100. doi:10.1007/s10488-006-0083-X

Noble, L. M., \& Douglas, B. C. (2004). What users and relatives want from mental health services. Current Opinion in Psychiatry, 17, 289-296. doi:10.1097/01.yco.0000-133832.42167.76

Organisation for Economic Co-operation and Development. (2003). Transforming disability into ability: Policies to promote work and income security for disabled people. Paris, France: OECD Publications.

Organisation for Economic Co-operation and Development. (2010). Sickness, disability and work: Breaking the barriers - Canada: Opportunities for collaboration. Retrieved from www.oecd.org/dataoecd/16/13/46093870.pdf

Parkinson, S., Nelson, G., \& Horgan, S. (1999). From housing to homes: A review of the literature on housing approaches for psychiatric consumer/survivors. Canadian Journal of Community Mental Health, 18(1), $145-164$. Retrieved from http://www.cjcmh.com/e/index.htm

Research Alliance for Canadian Homelessness, Housing, and Health. (2010). Housing vulnerability and health: Canada's hidden emergency (The Homeless Hub Report Series, Report \#2). Retrieved from St. Michael's Hospital website, http:/www.stmichaels hospital.com/pdf/crich/housing-vulnerability-and-health.pdf

Rogers, E. S., Danley, K. S., Anthony, W. A., Martin, R., \& Walsh, D. (1994). The residential needs and preferences of persons with serious mental illness: A comparison of consumers and family members. Journal of Behavioral Health Services \& Research, 21, 42-51. doi:10.1007/BF02521344

Saunders, J. C. (2003). Families living with severe mental illness: A literature review. Issues in Mental Health Nursing, 24(2), 175-198. doi:10.1080/01612840390160711

Sealy, P., \& Whitehead, P. C. (2006). The impact of deinstitutionalizing psychiatric services on the accessing of mental health services by people with higher levels of psychological distress. Canadian Journal of Community Mental Health, 25(1), 1-15. Retrieved from http://www.cjcmh.com/e/index.htm

Tanzman, B. (1993). An overview of surveys of mental health consumers' preferences for housing and support services. Hospital and Community Psychiatry, 44(5), 450-455.

Vozoris, N. T., \& Tarasuk, V. S. (2003). Household food insufficiency is associated with poorer health. Journal of Nutrition, 133(1), 120-126. Retrieved from http://jn.nutrition.org/

Wellesley Institute. (2010). Precarious housing in Canada. Retrieved from http://www.wellesleyinstitute.com/news/ new-report-precarious-housing-in-canada-2010/

Wilkinson, S., \& Himstedt, K. (2008). Establishing an innovative model of nutrition and dietetic care for a mental health service through collaboration with non-nutrition healthcare workers. Nutrition \& Dietetics, 65(4), $279-283$. doi:10.1111/j.1747-0080.2008.00310.x 